Original Article

\title{
The enduring effects of early-childhood adversities and troubled sleep among Canadian adults: a population-based study
}

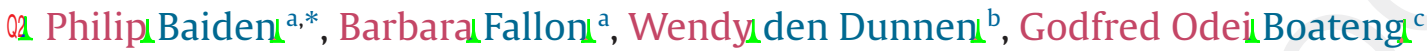 \\ a Factor-Inwentash Faculty of Social Work, University of Toronto, 246 Bloor Street West, Toronto, ON, Canada M5S 1V4 \\ b School of Psychology, University of Ottawa, 136 Jean Jacques Lussier, Vanier Hall, Ottawa, ON, Canada K1N 6N5 \\ Q3. c Department of Sociology,1151 Richmond Street, Social Science Centre, Western University, London, ON, Canada N6A 5C2
}

\section{A R T I C L E I N F O}

\section{Article history:}

Received 3 November 2014

Received in revised form 21 February 2015

Accepted 25 February 2015

Available online

\section{Keywords:}

Early-childhood adversities

Troubled sleep

Health

Mental health

Canada

\begin{abstract}
A B S T R A C T
Objective: Although many studies have consistently found that early-childhood adversities are important risk factors for physical and mental health problems later in adulthood, few have examined the association between early-childhood adversities and troubled sleep. The objective of this study was to examine the association between early-childhood adversities and troubled sleep among adult Canadians. Methods: Data for this paper $(N=19,349)$ were obtained from Statistics Canada's 2012 Canadian Community Health Survey - Mental Health (CCHS-MH). Logistic regression analysis was conducted to examine the association between adverse childhood adversities and troubled sleep, while accounting for various sociodemographic, socioeconomic, health, and mental health factors.

Results: Of the 19,349 respondents examined, 2748 representing $14.2 \%$ had troubled sleep. Controlling for sociodemographic, socioeconomic, health, and mental health factors, it was observed that for each additional childhood adversity experienced, the odds of having troubled sleep increased by $10 \%$ (odds ratio $(\mathrm{OR})=1.10, p<0.001,95 \%$ confidence interval $(\mathrm{CI})=1.07-1.13)$. In addition, psychological distress, older age, being female, being unmarried, being white, a lower annual income, chronic pain, poor perceived health, and mental health difficulties were associated with troubled sleep.

Conclusion: The results from this paper provide population-based evidence for childhood adversities as a major predictor of troubled sleep in adulthood. The long-standing effects of these adversities on sleep highlight the importance of early detection, such as consistent assessment of sleep habits for children, adolescents, and adults, who have experienced childhood adversities, in health and mental health settings.
\end{abstract} (c) 2015 Elsevier B.V. All rights reserved.

\section{Introduction}

A good night's sleep is considered important in maintaining both physical and mental health; however, sleep difficulties are common for many Canadians. Sleep problems may include difficulty falling or staying asleep, disordered breathing while sleeping, insomnia, or parasomnias [1,2]. Among Canadians, the prevalence of sleep difficulties ranges from $20 \%$ to $25 \%$, with about $10 \%$ having severe sleep problems [3]. Findings from the US also suggest that about one in three adults have troubled sleep, with 10-15\% reporting severe sleep difficulties [4-6].

Sleep problems have been studied extensively and have been found to be associated with many physical and mental health problems, including impaired decision making [3,7], increased absenteeism and loss of productivity [8,9], decreased quality of life [4], poor physical health [10], depression and anxiety [11,12], risky

Q11 * Corresponding author. University of Toronto, Factor-Inwentash Faculty of Social Work, 246 Bloor Street West, Toronto, ON, Canada M5S 1V4. Tel.: +1 519701 1090, E-mail address: philip.baiden@mail.utoronto.ca (P. Baiden). health-related behaviors, such as heavy alcohol consumption and cigarette smoking $[6,13,14]$, and suicide-related behaviors $[11,15,16]$. Studies have also found high rates of obesity and weight gain among individuals with troubled sleep [14,17-20].

The existing literature has also consistently found that earlychildhood adversities, such as neglect, emotional, physical, and sexual abuse, are risk factors for physical and mental health problems later in adulthood [21-23]. Most of these studies have shown higher rates of poor physical health [24-26], obesity [18], anxiety and depression [27], personality disorders [28], aggression and attention deficithyperactivity disorder (ADHD) [29], substance use disorders [30], chronic conditions [31], and suicide-related behaviors [32,33] among adults with a history of childhood adversities.

Although numerous studies have examined the phenomenon of troubled sleep, few have examined the association between earlychildhood adversities and troubled sleep. Studies that have examined early-childhood adversities and troubled sleep have found a significant association. For example, Chapman et al. [34] analyzed data on $>17,000$ Americans and found that, compared to individuals with no history of childhood adversities, those with a history of childhood adversities were over two times more likely to report trouble 
falling or staying asleep. Koskenvuo et al. [13] also examined the link between childhood adversities and troubled sleep among Finnish adults and found that adults who experienced multiple childhood adversities were over three times more likely to have troubled sleep than their counterparts who did not experience any adversities growing up. This association persisted after adjusting for work status, use of psychotropic drugs, health behaviors, recent life events, and child-parent relationships.

One reason that has been proffered in trying to understand the link between early-childhood adversities and troubled sleep relates to the increased hyperarousal and hypervigilance, which often results from the experience of traumatic events [35]. Early and repeated trauma has been linked to elevated stress hormones in individuals. This prolonged elevation of stress hormones is hypothesized to alter the development of the central nervous system, including a dysregulated brain stem that is more easily startled and, thus, more prone to hyperarousal, hypervigilance, and a dysregulated neuroendocrine system, which regulates sleep arousal [36,37]. Increased hyperarousal in individuals who have post-traumatic stress disorder is thought to account for difficulties sleeping due to increased activity within the brain, making it hard to fall asleep-and stay asleep [35].

To the best of our knowledge, no study has examined the link between early-childhood adversities and troubled sleep within the Canadian context and only a few studies have examined this association within a North American sample [30,34]. Thus, the objective of this paper was to further examine the association between earlychildhood adversities and troubled sleep in adulthood using a large, representative sample from Canada. In addition, of the few studies examining this relationship, one Finnish study controlled for additional factors associated with sleep, such as health behaviors, work status, and recent life events [13]. The current study aims to add to the literature by examining whether experiencing childhood adversities continue to be significantly associated with sleep problems later in adulthood after accounting for various sociodemographic, socioeconomic, health, and mental health factors within a North American sample. We hypothesized that adults, who experienced childhood adversities before age 16 , would be more likely to have troubled sleep after accounting for the various control variables.

\section{Methods}

\subsection{Data}

This paper used data from Statistics Canada's 2012 Canadian Community Health Survey - Mental Health (CCHS-MH) public-use microdata files (PUMF). The CCHS-MH is a cross-sectional survey that collects information on factors influencing mental health through a multidisciplinary approach focusing on social and economic determinants of health. The CCHS-MH covers those living in the 10 provinces aged 15 years and above and uses a multistage cluster sampling design with a random sampling method to select a sample that is representative of the Canadian population [38]. Residents of the three territories, individuals living on reserves or other Aboriginal settlements, full-time members of the Canadian Forces, and institutionalized populations are excluded from the survey's coverage area. Those excluded constitute $<3 \%$ of the target population [38]. Some of the main objectives of the CCHS-MH were to: “(1) assess the mental health status of Canadians on both illness and positive mental health continuums through selected mental and substance disorders, mental health problems, and well-being, and (2) assess timely, adequate, and appropriate access to and utilization of formal and informal mental health services and supports, as well as perceived needs" [38, p. 3]. The 2012 CCHS-MH includes questions on physical and mental health, resilience, mental health service utilization, alcohol and substance use, early-childhood adversities, chronic conditions, pain and discomfort, troubled sleep, job stress, as well as income and sociodemographic characteristics.

There were 25,113 respondents, representing 28,314,716 Canadians in the 2012 CCHS-MH dataset. However, given that questions on early-childhood adversities were only asked to respondents aged 18 years and older, and because age was measured in 5-year groups, the sample used in this paper consists of the-19,349 respondents aged 20 years and older. To produce a sample that is equal to the original sample size and representative of the population of Canada, the population weight was adjusted by dividing each master weight by the average weight. This was done to maintain the original sample size while, at the same time, keeping the weighting structure recommended by Statistics Canada. The adjusted population weight was used in all the analyses.

\subsection{Dependent and independent variables}

The dependent variable examined in this paper was troubled sleep and it was measured as a binary variable. Survey respondents were asked to rate on a five-point Likert scale ranging from 1 (none of the time) to 5 (all of the time) how often they have trouble going to sleep or staying asleep. Respondents who indicated having troubled sleep "most of the time" and "all of the time" were coded as 1 (troubled sleep) and compared to their colleagues who indicated "none of the time," "a little of the time," and some of the time" who were coded as 0 (no troubled sleep). The decision to treat troubled sleep as a dichotomous variable to a greater extent was informed by sample size consideration. The distribution of troubled sleep and some of the ordinal variables was not proportional across the various categories but follows a binomial distribution, hence the decision to treat these variables as dichotomous variables. Although there is no agreeable definition and measurement of troubled sleep or insomnia, the most commonly used measure of troubled sleep in the epidemiologic literature $[8,9,39]$ tends to be the frequency of trouble going to sleep or staying asleep.

The main independent variable examined in this paper was earlychildhood adversities and it was measured using six questions that ask respondents about events that may have happened to them before they turned 16 years old, either in their school, in their neighborhood, or in their family: (1) How many times did you see or hear any one of your parents, stepparents, or guardians hit each other or another adult in your home? (2) How many times did an adult slap you on the face, head, or ears or hit or spank you with something hard to hurt you? (3) How many times did an adult push, grab, shove, or throw something at you to hurt you? (4) How many times did an adult kick, bite, punch, choke, burn you, or physically attack you in some way? (5) How many times did an adult force you or attempt to force you into any unwanted sexual activity, by threatening you, holding you down, or hurting you in some way? (6) How many times did an adult touch you against your will in any sexual way? By this, I mean anything from unwanted touching or grabbing, to kissing or fondling. These questions were only administered to respondents aged 18 years and older. The responses to each question was coded as 1 (never) to 5 (more than 10 times). Respondents who were coded as $2,3,4$, or 5 were considered to have experienced the event at least once and respondents who were coded as 1 were considered not to have experienced the event. A sum of earlychildhood adversity was created $(M=1.04, \mathrm{SD}=1.41$, range $=0-6)$ to arrive at the number of childhood adversities experienced before age 16 .

Control variables examined in this paper include age, measured as a categorical variable in groups of 10-year spans; gender coded as a binary variable with male as the reference category; immigrant status (nonimmigrant vs. immigrant); marital status (married, common-law, formerly married, and single/never married); 
postsecondary education (no vs. yes); and annual personal income, measured in increments of $\$ 10,000$.

Both self-perceived physical and mental health were originally measured as ordinal variables on a five-point Likert scale ranging from excellent to poor. However, these variables were dichotomized into two categories by collapsing excellent, very good, and good into one category, called "good" (score $=0$ ), whereas fair and poor were collapsed together into a category called "poor" (score =1). Chronic pain status refers to the degree of pain that is usually felt by the respondents and the extent to which such pain prevents the respondent from performing certain basic activities. Responses to chronic pain status were coded as 1 if the respondent indicated experiencing pain that prevents a few, some, or most activities. Those who reported having no pain or experienced some amount of pain that does not prevent them from carrying out any activity were coded as 0 . For chronic conditions, respondents were asked the following question: "Now I'd like to ask about certain long-term health conditions which you may have. We are interested in 'long-term conditions' which are expected to last or have already lasted 6 months or more and that have been diagnosed by a health professional." The list of chronic conditions include the following: asthma, arthritis (excluding fibromyalgia), back problems (excluding fibromyalgia and arthritis), high blood pressure, migraine headaches, diabetes, heart disease, cancer, and effects of a stroke. The chronic condition variable was a nominal variable and coded 0 if the respondent does not have any of the above chronic conditions, 1 if the respondent has only one chronic condition, and 2 if respondent has two or more chronic conditions. The body weight of adult respondents aged 20 years and over (except for pregnant women) was measured and assigned to one of the following categories, according to their body mass index (BMI): underweight/ normal body weight; overweight; and obese class I, II, and III. The BMI categories were adopted from a body weight classification system recommended by Health Canada and the World Health Organization (WHO), which has been widely used internationally.

Psychological distress was assessed using the K6, a standardized screening measure for nonspecific psychological distress [40]. Respondents were asked to rate their psychological distress on a five-point Likert scale ranging from 0 (None of the time) to 4 (All of the time) how often they feel: (1) nervous, (2) hopeless, (3) restless or fidgety, (4) so depressed that nothing can cheer you up, (5) that everything is an effort, and (6) worthless. Scores on the psychological distress scale range from 0 to 24 with higher scores indicating more psychological distress. The $\mathrm{K} 6$ has been found to be a valid measure of psychological distress with strong internal consistency and adequate test-retest reliability [40-42]. In the present paper, internal consistency (Cronbach's $\alpha$ ) for the K6 was $\alpha=0.78$. Lastly, we controlled for the following mental health diagnoses: general anxiety disorder, major depressive episode, and alcohol or drug dependence. Each of these was measured as a binary variable and coded 1 , if the respondent was diagnosed; otherwise, it was coded as 0 .

\subsection{Statistical analyses}

Data were analyzed using bivariate and multivariate analytic techniques. First, the distribution of the dependent variable (troubled sleep) was examined. Next, a one-way analysis of variance (ANOVA) was conducted to examine whether the average psychological distress scores significantly differed for respondents who have troubled sleep from their counterparts who do not. Bivariate associations between troubled sleep and the categorical variables were also conducted using the Pearson chi-squared test of association. Given that the omnibus Pearson chi-square value does not specify which combination of categories contributes most to statistical significance, categorical variables with more than two categories are examined in detail in the logistic regression. Finally, a multivariate binary logistic regression model was fitted using the enter procedure to identify the predictors of troubled sleep. Binary logistic regression was chosen because the dependent variable had a binomial distribution and the independent variables were measured as both categorical and continuous variables $[43,44]$. Control variables were entered in Model 1. Model 2 consists of all the control variables plus the early-childhood adversity score. Model fitness was assessed using the omnibus chi-squared test, the percentage of respondents correctly classified as having troubled sleep versus no troubled sleep, as well as sensitivity and specificity ratios. The classification cutoff was adjusted to $14 \%$ to reflect the proportion of respondents who have troubled sleep. Adjusted odds ratios (ORs) are reported together with their 95\% confidence intervals (CIs). All analyses were performed using SPSS version 21 for Windows (SPSS Inc., Chicago, IL, USA) and variables were considered significant if the $p$-value was $<0.05$.

\section{Results}

\subsection{Prevalence of troubled sleep and early-childhood adversities}

Of the 19,349 respondents examined, 2748 (representing 14.2\%) had troubled sleep. Early-childhood adversities relating to physical abuse were more prevalent. For instance, $40.3 \%$ of the respondents were slapped in the face, hit, or spanked by an adult; $21.2 \%$ were pushed, grabbed, or shoved; and $10.2 \%$ were physically attacked (kicked/bitten/punched/choked/burned). About 16.0\% of the respondents witnessed domestic violence and $10.0 \%$ experienced unwanted sexual touching, kissing, or fondling. Lastly, 6.1\% of the respondents experienced forced or attempted forced sexual activity. About one in two respondents (49.6\%) experienced at least one of these adversities.

\subsection{Bivariate association between troubled sleep and psychological distress}

Table 1 displays the relationship between troubled sleep and psychological distress. The results indicate that the average psychological distress scores for respondents who had troubled sleep was significantly greater than respondents who did not have troubled sleep $\left(M_{\text {no troubled sleep }}=2.60\right.$ versus $M_{\text {troubled sleep }}=5.19, F(1,19,346)=1502.23$, $p<0.001)$.

\subsection{Bivariate association between troubled sleep and categorical explanatory variables}

The significant bivariate associations between troubled sleep and the categorical variables presented in Table 2, to a large extent, were consistent with what was expected. The proportion of respondents who experienced early-childhood adversities (across the six early-childhood adversities) and had troubled sleep was significantly greater than the proportion of respondents who had not experienced early-childhood adversities and had troubled sleep. A little over $11 \%$ of males compared to $17 \%$ of females reported having

\section{Table 1}

ANOVA result examining the relationship between troubled sleep and psychological distress $(N=19,349)$.

\begin{tabular}{|c|c|c|c|c|}
\hline \multirow[t]{2}{*}{ Variables } & $\begin{array}{l}\text { No troubled } \\
\text { sleep }\end{array}$ & $\begin{array}{l}\text { Troubled } \\
\text { sleep }\end{array}$ & Sig. & $F$ value (df) \\
\hline & Mean (SD) & Mean (SD) & & \\
\hline $\begin{array}{l}\text { Psychological } \\
\text { distress score }\end{array}$ & $2.60(2.94)$ & $5.19(4.62)$ & 0.001 & $1502.23(1,19,346)$ \\
\hline
\end{tabular}


Table 2

Bivariate association between troubled sleep and explanatory variables $(N=19,349)$.

\begin{tabular}{|c|c|c|c|}
\hline Variables & $\begin{array}{l}\text { Sample } \\
\text { size }(N)\end{array}$ & $\begin{array}{l}\text { \%Troubled } \\
\text { Sleep }\end{array}$ & $\begin{array}{l}\text { Chi-square } \\
\text { (sig.) }\end{array}$ \\
\hline Age & & & $107.84(0.001)$ \\
\hline 20-29 years & 3143 & 12.3 & \\
\hline 30-39 years & 3381 & 10.6 & \\
\hline 40-49 years & 3894 & 12.9 & \\
\hline 50-59 years & 4068 & 17.7 & \\
\hline 60 years and above & 4863 & 16.1 & \\
\hline Gender & & & $149.07(0.001)$ \\
\hline Male & 9797 & 11.2 & \\
\hline Female & 9552 & 17.3 & \\
\hline Immigrant status & & & $96.02(0.001)$ \\
\hline Nonimmigrant & 14,470 & 15.6 & \\
\hline Immigrant & 4878 & 10.0 & \\
\hline Marital status & & & $142.91(0.001)$ \\
\hline Married & 10,356 & 12.1 & \\
\hline Common law & 2378 & 14.7 & \\
\hline Formerly married & 2772 & 20.9 & \\
\hline Single/never married & 3843 & 14.9 & \\
\hline Postsecondary graduate & & & $85.33(0.001)$ \\
\hline No & 6656 & 17.4 & \\
\hline Yes & 12,693 & 12.5 & \\
\hline Annual personal income & & & $286.59(0.001)$ \\
\hline No income $/<\$ 10,000$ & 1050 & 19.3 & \\
\hline$\$ 10,000$ to $\$ 19,999$ & 2384 & 20.8 & \\
\hline$\$ 20,000$ to $\$ 29,999$ & 4154 & 17.9 & \\
\hline$\$ 30,000$ to $\$ 39,999$ & 2594 & 14.7 & \\
\hline$\$ 40,000$ to $\$ 49,999$ & 2260 & 10.4 & \\
\hline$\$ 50,000$ and above & 6908 & 10.0 & \\
\hline Self-perceived physical health & & & $950.05(0.001)$ \\
\hline Good & 17,406 & 11.6 & \\
\hline Poor & 1944 & 37.3 & \\
\hline Self-perceived mental health & & & $842.94(0.001)$ \\
\hline Good & 17,898 & 12.1 & \\
\hline Poor & 1450 & 39.8 & \\
\hline $\begin{array}{l}\text { Pain prevents respondent from } \\
\text { performing certain basic activities }\end{array}$ & & & $886.10(0.001)$ \\
\hline No & 16,523 & 11.1 & \\
\hline Yes & 2827 & 32.3 & \\
\hline Chronic condition & & & $710.47(0.001)$ \\
\hline No chronic condition & 9585 & 8.3 & \\
\hline One chronic condition & 5284 & 15.8 & \\
\hline Two or more chronic conditions & 4481 & 24.9 & \\
\hline BMI category & & & $41.16(0.001)$ \\
\hline Underweight/Normal & 8940 & 13.0 & \\
\hline Overweight & 6583 & 14.0 & \\
\hline Obese & 3825 & 17.3 & \\
\hline Lifetime major depressive episode & & & $696.59(0.001)$ \\
\hline No & 17,069 & 11.8 & 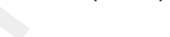 \\
\hline Yes & 2280 & 32.3 & \\
\hline Lifetime general anxiety disorder & & & $573.29(0.001)$ \\
\hline No & 17,577 & 12.3 & \\
\hline Yes & 1772 & 33.1 & \\
\hline Lifetime alcohol dependence & & & $62.99(0.001)$ \\
\hline No & 18,709 & 13.8 & \\
\hline Yes & 641 & 25.0 & \\
\hline Witnessed domestic violence & & & $109.52(0.001)$ \\
\hline No & 16,359 & 13.1 & \\
\hline Yes & 2989 & 20.3 & \\
\hline $\begin{array}{l}\text { Slapped in the face, hit, or spanked by } \\
\text { an adult }\end{array}$ & & & $127.27(0.001)$ \\
\hline No & 11,559 & 11.9 & \\
\hline Yes & 7790 & 17.7 & \\
\hline Pushed, grabbed, or shoved & & & $203.54(0.001)$ \\
\hline No & 15,243 & 12.3 & \\
\hline Yes & 4105 & 21.1 & \\
\hline $\begin{array}{l}\text { Physically attacked (kicked/bitten/ } \\
\text { punched/choked/burned) }\end{array}$ & & & $212.93(0.001)$ \\
\hline No & 17,374 & 13.0 & \\
\hline Yes & 1975 & 25.1 & \\
\hline $\begin{array}{l}\text { Experienced forced or attempted } \\
\text { forced sexual activity }\end{array}$ & & & $264.28(0.001)$ \\
\hline No & 18,162 & 13.2 & \\
\hline Yes & 1187 & 30.2 & \\
\hline $\begin{array}{l}\text { Experienced unwanted sexual } \\
\text { touching, kissing, or fondling }\end{array}$ & & & $274.87(0.001)$ \\
\hline No & 17,409 & 12.8 & \\
\hline Yes & 1939 & 26.7 & \\
\hline
\end{tabular}

troubled sleep $\left(\chi^{2}(1)=149.07, p<0.001\right)$. The proportion of nonimmigrants who reported having troubled sleep (15.6\%) was significantly greater than the proportion of immigrants who had troubled sleep $(10 \%)\left(\chi^{2}(1)=96.02, p<0.001\right)$. Respondents were more likely to have troubled sleep if they were older, single/never married, formerly married, or in a common-law relationship; if they had less than postsecondary education; or if they had low annual income. Furthermore, respondents were more likely to have troubled sleep if they perceived their physical or mental health to be poor, experienced chronic pain, reported having some chronic condition, or were overweight or obese. All the three mental health diagnoses examined were also significantly associated with troubled sleep.

\subsection{Multivariate logistic regression predicting the odds of having troubled sleep}

Although the independent and control variables were significantly associated with troubled sleep at the bivariate level, there were no controls at this level so we were unable to ascertain the relative contribution of each variable in explaining troubled sleep. In the multivariate analysis, we controlled for the effect of all the explanatory, variables in predicting troubled sleep. All the model diagnostic statistics indicated that the multivariate model was fit and both the independent and control variables made significant contributions to the model. Based on the Nagelkerke pseudo $R^{2}$, earlychildhood adversities and the control variables explained about $20 \%$ of the variance in troubled sleep. In the final model, approximately $73 \%$ of the respondents were correctly classified as having troubled sleep versus no troubled sleep. Roughly $75 \%$ of respondents were observed and correctly predicted to have troubled sleep (sensitivity), whereas $67 \%$ were observed as not having troubled sleep and were correctly predicted to not have troubled sleep (specificity).

Controlling for all other factors in Table 3, Model 2, for each additional childhood adversity experienced, the odds of having troubled sleep were predicted to increase by a factor of $10 \%$, net the effect of all the other factors ( $\mathrm{OR}=1.10, p<0.001,95 \% \mathrm{CI}=1.07-1.13)$. In addition, for every increase in psychological distress scores, the odds of having troubled sleep were predicted to increase by a factor of $10 \%(\mathrm{OR}=1.10, p<0.001,95 \% \mathrm{CI}=1.09-1.12)$. Respondents who were between 50 and 59 years of age were 1.47 times more likely to have troubled sleep when compared to respondents aged 20-29 years $(\mathrm{OR}=1.47, p<0.001,95 \% \mathrm{Cl}=1.24-1.74)$. Compared to males, the odds were $36 \%$ higher for females to have troubled sleep ( $O R=1.36$, $p<0.001,95 \% \mathrm{CI}=1.23-1.49$ ). The odds were $29 \%$ less likely for immigrants to have troubled sleep when compared to their nonimmigrant counterparts ( $\mathrm{OR}=0.71, p<0.001,95 \% \mathrm{CI}=0.64-0.80)$. With respect to marital status, respondents who were single/ never married $(\mathrm{OR}=1.201, p=0.008,95 \% \mathrm{CI}=1.05-1.38)$, formerly married $(\mathrm{OR}=1.33, p<0.001,95 \% \mathrm{CI}=1.18-1.50)$, or living in a common-law relationship $(\mathrm{OR}=1.20, p=0.015,95 \% \mathrm{CI}=1.04-1.39)$ were more likely to have troubled sleep when compared to respondents who were married. For every increase in annual income by $\$ 10,000$, the odds of respondents having troubled sleep were predicted to decrease by $7 \%$ holding all other factors in the model constant $(\mathrm{OR}=0.93, p<0.001,95 \% \mathrm{CI}=0.90-0.96)$. Compared to respondents with no chronic condition, respondents who had one chronic condition were 1.56 times more likely to have troubled sleep $(\mathrm{OR}=1.56, p<0.001,95 \% \mathrm{CI}=1.40-1.75)$, and the odds were 1.81 times higher for respondents who had two or more chronic conditions to have troubled sleep $(\mathrm{OR}=1.81, p<0.001,95 \% \mathrm{CI}=1.60-2.06)$. Respondents were also more likely to have troubled sleep if they: perceived their physical and mental health to be poor, had pain that prevented them from performing certain basic activities, or had a lifetime diagnosis of major depressive episode or general anxiety 
Table 3

Multivariate logistic regression predicting the likelihood of having troubled sleep.

\begin{tabular}{|c|c|c|c|c|c|c|}
\hline \multirow[t]{2}{*}{ Characteristics } & \multicolumn{3}{|c|}{ Model 1} & \multicolumn{3}{|c|}{ Model 2} \\
\hline & $B$ & Sig & $\operatorname{Exp}(B)(95 \% C I)$ & $B$ & Sig & $\operatorname{Exp}(B)(95 \% C I)$ \\
\hline \multicolumn{7}{|l|}{ Age (20-29 years) } \\
\hline $30-39$ years & -0.081 & 0.365 & $0.92(0.77-1.10)$ & -0.102 & 0.254 & $0.90(0.76-1.08)$ \\
\hline 40-49 years & -0.024 & 0.782 & $0.98(0.82-1.16)$ & -0.063 & 0.481 & $0.94(0.79-1.12)$ \\
\hline $50-59$ years & 0.416 & 0.001 & $1.52(1.28-1.80)$ & 0.385 & 0.001 & $1.47(1.24-1.74)$ \\
\hline 60 years and above & 0.126 & 0.169 & $1.13(0.95-1.36)$ & 0.128 & 0.160 & $1.14(0.95-1.36)$ \\
\hline \multicolumn{7}{|l|}{ Gender (male) } \\
\hline Female & 0.298 & 0.001 & $1.35(1.23-1.48)$ & 0.304 & 0.001 & $1.36(1.23-1.49)$ \\
\hline \multicolumn{7}{|l|}{ Immigrant status (nonimmigrant) } \\
\hline Immigrant & -0.342 & 0.001 & $0.71(0.63-0.80)$ & -0.340 & 0.001 & $0.71(0.64-0.80)$ \\
\hline \multicolumn{7}{|l|}{ Marital status (married) } \\
\hline Common law & 0.187 & 0.012 & $1.21(1.04-1.40)$ & 0.182 & 0.015 & $1.20(1.04-1.39)$ \\
\hline Formerly married & 0.282 & 0.001 & $1.33(1.17-1.50)$ & 0.283 & 0.001 & $1.33(1.18-1.50)$ \\
\hline Single/never married & 0.190 & 0.007 & $1.21(1.05-1.39)$ & 0.186 & 0.008 & $1.20(1.05-1.38)$ \\
\hline \multicolumn{7}{|l|}{ Postsecondary graduate (no) } \\
\hline Yes & -0.086 & 0.077 & $0.92(0.83-1.01)$ & -0.085 & 0.081 & $0.92(0.83-1.01)$ \\
\hline Annual personal income & -0.076 & 0.001 & $0.93(0.90-0.96)$ & -0.076 & 0.001 & $0.93(0.90-0.96)$ \\
\hline \multicolumn{7}{|l|}{ Self-perceived physical health (good) } \\
\hline Poor & 0.563 & 0.001 & $1.76(1.54-2.00)$ & 0.566 & 0.001 & $1.76(1.55-2.01)$ \\
\hline \multicolumn{7}{|l|}{ Self-perceived mental health (good) } \\
\hline Poor & 0.226 & 0.004 & $1.25(1.08-1.46)$ & 0.207 & 0.008 & $1.23(1.06-1.43)$ \\
\hline \multicolumn{7}{|l|}{ Chronic condition (none) } \\
\hline One chronic condition & 0.461 & 0.001 & $1.59(1.42-1.77)$ & 0.446 & 0.001 & $1.56(1.40-1.75)$ \\
\hline Two or more chronic conditions & 0.619 & 0.001 & $1.86(1.64-2.11)$ & 0.595 & 0.001 & $1.81(1.60-2.06)$ \\
\hline \multicolumn{7}{|c|}{ Pain prevents respondent from performing certain activities (no) } \\
\hline Yes & 0.491 & 0.001 & $1.63(1.46-1.83)$ & 0.475 & 0.001 & $1.61(1.44-1.80)$ \\
\hline \multicolumn{7}{|l|}{ BMI category (underweight/normal) } \\
\hline Overweight & 0.087 & 0.097 & $1.09(0.98-1.21)$ & 0.086 & 0.101 & $1.09(0.98-1.21)$ \\
\hline Obese & 0.021 & 0.725 & $1.02(0.91-1.15)$ & 0.016 & 0.793 & $1.02(0.90-1.14)$ \\
\hline \multicolumn{7}{|l|}{ Lifetime major depressive episode (no) } \\
\hline Yes & 0.546 & 0.001 & $1.73(1.53-1.95)$ & 0.514 & 0.001 & $1.67(1.48-1.89)$ \\
\hline \multicolumn{7}{|l|}{ Lifetime general anxiety disorder (no) } \\
\hline Yes & 0.194 & 0.005 & $1.21(1.06-1.39)$ & 0.170 & 0.015 & $1.19(1.03-1.36)$ \\
\hline \multicolumn{7}{|l|}{ Lifetime alcohol dependence (no) } \\
\hline Yes & 0.087 & 0.422 & $1.09(0.88-1.35)$ & 0.007 & 0.952 & $1.01(0.81-1.25)$ \\
\hline Psychological distress & 0.103 & 0.001 & $1.11(1.09-1.12)$ & 0.097 & 0.001 & $1.10(1.09-1.12)$ \\
\hline Early-childhood adversity score & & & & 0.094 & 0.001 & $1.10(1.07-1.13)$ \\
\hline Nagelkerke pseudo $R^{2}$ & & & 0.197 & & & 0.200 \\
\hline Model chi-square (sig) & & & $2253.23(0.001)$ & & & $2292.29(0.001)$ \\
\hline Sensitivity & & & 73.9 & & & 74.5 \\
\hline Specificity & & & 65.3 & & & 66.6 \\
\hline Overall percentage correctly classified & & & 72.7 & & & 73.4 \\
\hline
\end{tabular}

Reference categories are identified in brackets.

disorder. Postsecondary education, body weight, and a lifetime diagnosis of alcohol dependence failed to reach statistical significance.

To examine whether the impact of troubled sleep differs depending on the type of adversity experienced, we reexamined the association between early-childhood adversity (" 0 = no early adversities," "1 = only witnessed domestic violence," "2 = only slapped

Table 4

Multivariate logistic regression examining the association between early-childhood Q8 adversity and troubled sleep.

\begin{tabular}{|c|c|c|c|}
\hline Characteristic & $B$ & Sig & $\operatorname{Exp}(B)(95 \%$ C.I $)$ \\
\hline \multicolumn{4}{|l|}{ Early-childhood adversity (none) } \\
\hline Witnessed domestic violence & 0.014 & 0.924 & $1.01(0.76-1.36)$ \\
\hline $\begin{array}{l}\text { Slapped in the face, hit or spanked by an } \\
\text { adult }\end{array}$ & 0.341 & 0.001 & $1.41(1.25-1.58)$ \\
\hline Pushed, grabbed, or shoved & 0.100 & 0.537 & $1.11(0.81-1.52)$ \\
\hline $\begin{array}{l}\text { Physical attacked (kicked/bitten/ } \\
\text { punched/choked/burned) }\end{array}$ & 0.897 & 0.001 & $2.45(1.46-4.10)$ \\
\hline $\begin{array}{l}\text { Experienced forced or attempted forced } \\
\text { sexual activity }\end{array}$ & 0.621 & 0.291 & $1.86(0.59-5.90)$ \\
\hline $\begin{array}{l}\text { Experienced unwanted sexual touching, } \\
\text { kissing, or fondling }\end{array}$ & 1.060 & 0.001 & $2.87(2.17-3.83)$ \\
\hline $\begin{array}{l}\text { Experienced multiple incidents of } \\
\text { adversities }\end{array}$ & 0.758 & 0.001 & $2.13(1.94-2.34)$ \\
\hline
\end{tabular}

Reference category is identified in brackets. in the face, hit or spanked by an adult," " $3=$ only pushed, grabbed, or shoved (kicked/bitten/punched/choked/burned)," " $4=$ only experienced forced or attempted forced sexual activity," " $5=$ only experienced unwanted sexual touching, kissing, or fondling," and " 6 = experienced multiple incidents of adversities") and troubled sleep using logit regression. The results presented in Table 4 indicate that respondents who experienced only unwanted sexual touching, kissing, or fondling were 2.87 times more likely to have troubled sleep $(\mathrm{OR}=2.87, p<0.001,95 \% \mathrm{CI}=2.17-3.83)$; those who were only physically attacked were 2.45 times more likely to have troubled sleep $(\mathrm{OR}=2.45, p<0.001,95 \% \mathrm{CI}=1.46-4.10)$; those who were only slapped in the face, hit, or spanked by an adult were 1.41 times more likely to have troubled sleep $(\mathrm{OR}=1.41, p<0.001,95 \%$ $\mathrm{CI}=1.25-1.58$ ); and those who experienced multiple incidents of adversities were 2.13 times more likely to have troubled sleep $(\mathrm{OR}=2.13, p<0.001,95 \% \mathrm{CI}=1.94-2.34)$, all when compared to respondents who experienced no early-childhood adversities.

\section{Discussion}

Using a large dataset from Canada, this paper investigated the association between early-childhood adversities and troubled sleep in adulthood. Consistent with past studies $[3,4,39]$, we found that $14 \%$ of Canadians had troubled sleep. Excluding Aboriginal
73 74 75 76 77 78 
individuals, members of the armed forces, and institutional populations may have impacted the prevalence rate of troubled sleep reported in this paper as some studies have found prevalence rates of troubled sleep among these individuals to be high $[45,46]$. However, given that this population constituted $<3 \%$ of the sample, their impact, if any, would be minimal on the prevalence rate of troubled sleep reported in this study.

Although some studies have examined factors associated with troubled sleep in adulthood, few have examined the link between early adversities and troubled sleep. This paper found that experience of early-childhood adversities significantly increases the odds of having difficulty falling or staying asleep among Canadian adults. This key finding is consistent with previous literature, which has found that adverse experiences during childhood and adolescence are risk factors for sleep problems in later life [34,35].

This study also identified that more severe and chronic types of childhood adversities, such as sexual, physical, and multiple types of abuse, have the largest association with sleep problems. This is consistent with research that has identified that chronically maltreated children tend to have more mental health and social challenges than children who have experienced transient maltreatment [47]. In addition, severe abuse, such as chronic sexual and physical abuse, has been associated with increased mental health problems in adulthood, including post-traumatic stress disorder, which often involves difficulty sleeping. In fact, the effects of chronic interpersonal maltreatment is often referred to as complex posttraumatic stress disorder, due to the increased intensity and severity of the distress experienced by these individuals when compared to individuals who have experienced non-chronic forms of maltreatment (e.g., Refs. $[48,49])$.

The higher association between more framatizing forms of childhood maltreatment (i.e., chronic and severe) and sleep is consistent with Gaensbauer and Jordan's [50] theory that individuals who have been traumatized may develop maladaptive strategies to cope with their abusive history and/or become hyperaroused when confronted with acute stressors in adulthood. These maladaptive strategies and the increased hyperarousal can then increase troubled sleep [35]. This may be especially true for adults who experienced child sexual abuse; for these individuals, bedtime may be a trigger for their traumatic experiences. Therefore, adults with child trauma histories and sleep problems may benefit from the consistent use of relaxation techniques that increase the body and brain's familiarity with less aroused states of being. However, for individuals who reexperience the trauma when trying to sleep or have severe symptoms of hyperarousal, a more intensive, trauma-focused intervention that includes relaxation training may be more beneficial.

Another possible explanation for the association between childhood adversity and troubled sleep is that many children who experience maltreatment grow up in disorganized family environments that lack a model of good sleep hygiene, such as bedtime routines and reduced noise levels. Prolonged exposure to poor sleep hygiene can then manifest into poor sleep patterns, which may persist into adulthood [35]. In support of this, Gregory, Caspi, Moffitt, and Poulton [51] found that family chaos is significantly correlated with sleep problems in childhood. Thus, in cases where adults have not been exposed to good sleep hygiene models due to chaotic and traumatic childhood experiences, it may be especially to provide psychoeducation and help them develop an environment and routine that is more conducive to sleep.

The current paper found perceived poor physical and mental health, psychological distress, and lifetime diagnoses of major depressive episodes and general anxiety disorder as significant predictors of troubled sleep, which is consistent with previous literature $[6,12,14]$ and the current general understanding of psychological distress. A symptom of both depression and anxiety is fatigue and sleep difficulties [52]. In addition, anxiety and rumination have been identified as important factors in maintaining sleep difficulties and insomnia because these cognitive processes trigger hyperarousal and emotional distress, increasing one's difficulty falling asleep [53].

Furthermore, respondents who had chronic health conditions or pain that prevents them from performing certain basiçactivities were found to be at an elevated risk of having troubled sleep. Similarly, extant research has consistently found that chronic and acute health problems that induce pain affect sleep, as well as daily functioning. Individuals who experience pain at night often report difficulty falling and staying asleep as a result of the discomfort. Indeed, Moldofsky [54] argues that the link between sleep and bodily pain, as well as fatigue and psychological distress, has been known for $>4000$ years. We failed to find any association between obesity and troubled sleep, although some studies have found this association to hold after adjusting for other demographic and health factors. The nonsignificant finding reported in this paper may be due to the exclusion of pregnant women in the computation of BMI. Some studies have observed an increased incidence of troubled sleep during pregnancy with most symptoms prevalent during the third trimester $[55,56]$.

Consistent with past studies [57,58], this paper found a significant association between marital status and troubled sleep with unmarried adults more likely to have sleep problems. The unmarried are more likely to experience loneliness, which in turn may compromise the body's rejuvenating functions by disturbing sleep or hindering sleep's recuperative effect [59]. Being married therefore provides an emotional support system for dealing with stress, which in turn increases the quality of sleep. However, it is worth noting that highly strained relationships, lack of emotional support, and coughing and snoring when sharing a bed may also increase sleep difficulties in marriages, as noted by some scholars [60]. Consequently, the quality of sleep for married individuals is conditioned on a good relationship and sound health.

Researchers [61,62] have posited that sleep complaints are common in all ages; nonetheless, their prevalence increases with age. We found a similar trend in Canada, as older adults, relative to younger ones, had significantly increased likelihood of having troubled sleep. Epidemiological studies have shown that older adults have less slow-wave sleep (deep sleep) and rapid eye movement sleep, which affects their quality of sleep compared to those in their youthful years $[63,64]$. This may account for the differences seen between the older and the younger generation.

The current study found that Canadian females are more likely to have difficulty falling and staying asleep, which is consistent with most previous studies that assess troubled sleep rather than the quantity of sleep $[65,66]$. With regard to quantity, it has been found that males report less sleep [67]. It is well established in the literature that females are more likely to have internalizing problems, such as anxiety and depressive symptoms, and chronic pain (e.g., Refs. [68,69]). This may partially explain the gender difference, given that both internalizing problems and chronic pain are also associated with troubled sleep.

\subsection{Limitations}

Notwithstanding the interesting findings, this paper has some limitations that are also opportunities for future research. First, the cross-sectional nature of the data limits our ability to make causal claims on the temporal order between some of the covariates and troubled sleep. Additional studies that use longitudinal data are warranted. Second, most of the information collected is self-reported and, thus, is subject to recall bias. Lastly, changing the underlying levels of measurement of an ordinal variable into a dichotomous variable has the potential to affect the effect size of some of the results reported in this paper. However, the decision to recode ordinal 
variables into dichotomous variables in the current study was informed by the fact that the distribution on most of the ordinal variables was not proportional across the various categories. In these situations, it is recommended that ordinal variables be treated as dichotomous variables [44].

\subsection{Implications and future research}

In summary, the results from this paper provide populationbased evidence for childhood adversities as a major predictor of troubled sleep in adulthood. They highlight the importance of exploring sleep habits for children, adolescents, and adults who have experienced childhood maltreatment in health and mental health settings. Identifying sleep problems early and making appropriate referrals may help reduce the long-term effects of these adverse experiences on sleep, particularly for those who experienced sexual, physical, or multiple types of childhood maltreatment. Although this study identified that severe forms of childhood adversity are more highly associated with sleep problems than less severe forms, identifying the mechanism underlying the relationship between childhood adversity and sleep problems was beyond the scope of the current paper. For example, how do the characteristics of the sleep problem (e.g., onset of problems, type of sleep problem, intensity and severity of the sleep problem, presence of traumarelated symptoms at bedtime, etc.) and the childhood adversity (e.g., frequency of adversity, age at onset of adversity, duration of adversity, social support at time of adversity, etc.) impact the relationship? This is an important area for future research, especially given the negative health and mental health outcomes associated with both childhood adversity and long-term sleep problems. Obtaining more information on the mechanisms underlying the relationship will allow for more targeted and evidence-based prevention and intervention efforts to reduce the long-term impact of childhood adversity and sleep problems.

\section{Conflict of interest}

The authors declare that they had no conflicts of interests with respect to their authorship and/or the publication of this paper.

The ICMJE Uniform Disclosure Form for Potential Conflicts of Interest associated with this article can be viewed by clicking on the following link: http://dx.doi.org/10.1016/j.sleep.2015.02.527.

\section{Acknowledgments}

This research was supported in part by a Joseph-Armand Bombardier Canada Graduate Scholarship-Doctoral Award through the Social Sciences and Humanities Research Council of Canada and funding from the Lupina Foundation both awarded to the first author. This research was based on data collected by Statistics Canada. The views and opinions expressed in this paper are those of the authors and do not represent the views of Statistics Canada.

\section{References}

[1] Al Mamun A, O'Callaghan F, Scott J, et al. Continuity and discontinuity of trouble sleeping behaviors from early childhood to young adulthood in a large Australian community-based-birth cohort study. Sleep Med 2012;13(10):1301-6.

[2] Ohayon MM. Difficulty in resuming or inability to resume sleep and the links to daytime impairment: definition, prevalence and comorbidity. J Psychiatr Res 2009;43(10):934-40.

[3] Fortier-Brochu É, Beaulieu-Bonneau S, Ivers H, Morin CM. Insomnia and daytime cognitive performance: a meta-analysis. Sleep Med Rev 2012;16(1):83-94

[4] LeBlanc M, Beaulieu-Bonneau S, Mérette C, Savard J, Ivers H, Morin CM. Psychological and health-related quality of life factors associated with insomnia in a population-based sample. J Psychosom Res 2007;63(2):157-66.

[5] Ohayon MM. Nocturnal awakenings and comorbid disorders in the American general population. J Psychiatr Res 2008;43(1):48-54.
[6] Pearson NJ, Johnson LL, Nahin RL. Insomnia, trouble sleeping, and complementary and alternative medicine: analysis of the 2002 national health interview survey data. Arch Intern Med 2006;166(16):1775-82.

[7] Kendall AP, Kautz MA, Russo MB, Killgore WD. Effects of sleep deprivation on lateral visual attention. Int J Neurosci 2006;116(10):1125-38.

[8] Kling RN, McLeod CB, Koehoorn M. Sleep problems and workplace injuries in Canada. Sleep 2010;33(5):611-18.

[9] Ohayon MM, Lemoine P, Arnaud-Briant V, Dreyfus M. Prevalence and consequences of sleep disorders in a shift worker population. J Psychosom Res 2002;53(1):577-83.

[10] Vandekerckhove M, Cluydts R. The emotional brain and sleep: an intimate relationship. Sleep Med Rev 2010;14(4):219-26.

[11] Bernert RA, Joiner TE, Cukrowicz KC, Schmidt NB, Krakow B. Suicidality and sleep disturbances. Sleep 2005;28(9):1135.

[12] Krakow B, Zadra A. Clinical management of chronic nightmares: imagery rehearsal therapy. Behav Sleep Med 2006;4(1):45-70.

[13] Koskenvuo K, Hublin C, Partinen M, Paunio T, Koskenvuo M. Childhood adversities and quality of sleep in adulthood: a population-based study of 26,000 Finns. Sleep Med 2010;11(1):17-22.

[14] Strine TW, Chapman DP. Associations of frequent sleep insufficiency with health-related quality of life and health behaviors. Sleep Med 2005;6(1):23-7.

[15] Agargun MY, Besiroglu L. Sleep and suicidality: do sleep disturbances predict suicide risk? Sleep 2005;28(9):1039-40.

[16] Pigeon WR, Pinquart M, Conner K. Meta-analysis of sleep disturbance and suicidal thoughts and behaviors. J Clin Psychiatry 2012;73(9):e1160-7.

[17] Berkey CS, Rockett HRH, Colditz GA. Weight gain in older adolescent females: the internet, sleep, coffee, and alcohol. J Pediatr 2008;153(5):635, 639.e1.

[18] Bentley T, Widom CS. A 30-year follow-up of the effects of child abuse and neglect on obesity in adulthood. Obesity 2009;17(10):1900-5.

[19] Lyytikäinen P, Lallukka T, Lahelma E, Rahkonen O. Sleep problems and major weight gain: a follow-up study. Int J Obes 2010;35(1):109-14.

[20] Watson NF, Harden KP, Buchwald D, et al. Sleep duration and body mass index in twins: a gene-environment interaction. Sleep 2012;35(5):597-603.

[21] Geeraert L, Van den Noortgate W, Grietens H, Onghena P. The effects of early prevention programs for families with young children at risk for physical child abuse and neglect: a meta-analysis. Child Maltreat 2004;9(3):277-91.

[22] Miller AB, Esposito-Smythers C, Weismoore JT, Renshaw KD. The relation between child maltreatment and adolescent suicidal behavior: a systematic review and critical examination of the literature. Clin Child Fam Psychol Rev 2013;16(2):146-72.

[23] Fallon B, Chabot M, Fluke J, Blackstock C, MacLaurin B, Tonmyr L. Placement decisions and disparities among aboriginal children: further analysis of the Canadian incidence study of reported child abuse and neglect part A: comparisons of the 1998 and 2003 surveys. Child Abuse Negl 2013;37(1):4760.

[24] Rapoza KA, Wilson DT, Widmann WA, et al. The relationship between adult health and childhood maltreatment, as moderated by anger and ethnic background. Child Abuse Negl 2014;38(3):445-56.

[25] Widom CS, Czaja SJ, Bentley T, Johnson MS. A prospective investigation of physical health outcomes in abused and neglected children: new findings from a 30-year follow-up. Am J Public Health 2012;102(6):1135-44.

[26] Fallon B, Trocme N, MacLaurin B. Should child protection services respond differently to maltreatment, risk of maltreatment, and risk of harm? Child Abuse Negl 2011;35(4):236-9.

[27] Kendler K, Aggen S. Clarifying the causal relationship in women between childhood sexual abuse and lifetime major depression. Psychol Med 2014;44(06):1213-21.

[28] Spataro J, Mullen PE, Burgess PM, Wells DL, Moss SA. Impact of child sexual abuse on mental health: prospective study in males and females. Br J Psychiatry 2004;184:416-21.

[29] Fuller-Thomson E, Mehta R, Valeo A. Establishing a link between attention deficit disorder/attention deficit hyperactivity disorder and childhood physical abuse. J Aggr Maltr Trauma 2014;23(2):188-498.

[30] Anda RF, Felitti VJ, Bremner JD, et al. The enduring effects of abuse and related adverse experiences in childhood. Eur Arch Psychiatry Clin Neurosci 2006;256(3):174-486.

[31] Fuller-Thomson E, Brennenstuhl S. Making a link between childhood physical abuse and cancer. Cancer 2009;115(14):3341-50.

[32] Gladstone GL, Parker GB, Mitchell PB, Malhi GS, Wilhelm K, Austin M. Implications of childhood trauma for depressed women: an analysis of pathways from childhood sexual abuse to deliberate self-harm and revictimization. Am J Psychiatry 2004;161(8):1417-25.

[33] Joiner TE Jr, Sachs-Ericsson NJ, Wingate LR, Brown JS, Anestis MD, Selby EA. Childhood physical and sexual abuse and lifetime number of suicide attempts: a persistent and theoretically important relationship. Behav Res Ther 2007;45(3):539-47.

[34] Chapman DP, Wheaton AG, Anda RF, et al. Adverse childhood experiences and sleep disturbances in adults. Sleep Med 2011;12(8):773-9.

[35] Bader K, Schaefer V, Schenkel M, Nissen L, Schwander J. Adverse childhood experiences associated with sleep in primary insomnia. J Sleep Res 2007;16(3):285-96.

[36] Grayson J, Childress A, Ernst W, Baker W, Portective $C$. Maltreatment and its effects on early brain development. Virginia Child Proten 2006;77:1-6.

[37] Twardosz S, Lutzker JR. Child maltreatment and the developing brain: a review of neuroscience perspectives. Aggr Viol Behav 2010;15(1):59-68. 
[38] Statistics Canada. Canadian community health survey - mental health, 2012. Statistics Canada; 2013.

[39] Tjepkema M. Insomnia. Health Rep 2005;17(1).

[40] Kessler RC, Andrews G, Colpe LJ, et al. Short screening scales to monitor population prevalences and trends in non-specific psychological distress. Psychol Med 2002;32(06):959-76.

[41] Furukawa TA, Kessler RC, Slade T, Andrews G. The performance of the K6 and K10 screening scales for psychological distress in the Australian national survey of mental health and well-being. Psychol Med 2003;33(02):357-62.

[42] Kessler RC, Green JG, Gruber MJ, et al. Screening for serious mental illness in the general population with the K6 screening scale: results from the WHO world mental health (WMH) survey initiative. Int J Methods Psychiatr Res 2010;19(S1):4-22.

[43] Hosmer DW, Lemeshow S. Applied logistic regression. 2nd ed. New York: Wiley; 2000.

[44] Tabachnick BG, Fidell LS. Using multivariate statistics. 5th ed. Boston: Pearson/ Allyn \& Bacon; 2007.

[45] Brown CA, Berry R, Schmidt A. Sleep and military members: emerging issues and nonpharmacological intervention. Sleep Disorders 2013;2013.

[46] Froese CL, Butt A, Mulgrew A, et al. Depression and sleep-related symptoms in an adult, indigenous, north American population. J Clin Sleep Med 2008;4(4):356-61.

[47] Jaffee SR, Maikovich-Fong AK. Effects of chronic maltreatment and maltreatment timing on children's behavior and cognitive abilities. J Child Psychol Psyc 2011;52(2):184-94.

[48] Dorahy MJ, Corry M, Shannon M, et al. Complex PTSD, interpersonal trauma and relational consequences: findings from a treatment-receiving Northern Irish sample. J Affect Disorders 2009;112:71-80.

[49] Herman JL. Complex PTSD: a syndrome in survivors of prolonged and repeated trauma. J Trauma Stress 1992;5(3):377-91.

[50] Gaensbauer TJ, Jordan L. Psychoanalytic perspectives on early trauma: interviews with thirty analysts who treated an adult victim of a circumscribed trauma in early childhood. J Am Psychoanal Assoc 2009;57(4):947-77.

[51] Gregory AM, Caspi A, Moffitt TE, Poulton R. Family conflict in childhood: a predictor of later insomnia. Sleep 2006;29(8):1063.

American Psychiatric Association. Diagnostic and statistical manual of mental disorders. 5th ed. Arlington, Va.: American Psychiatric Association; 2013.

[53] Harvey AG. A cognitive model of insomnia. Behav Res Ther 2002;40(8):869-93.

[54] Moldofsky H. Sleep and pain. Sleep Med Rev 2001;5(5):385-96.
[55] Field T, Diego M, Hernandez-Reif M, Figueiredo B, Schanberg S, Kuhn C. Sleep disturbances in depressed pregnant women and their newborns. Infant Behav Dev 2007;30(1):127-33.

[56] Sahota PK, Jain SS, Dhand R. Sleep disorders in pregnancy. Curr Opin Pulm Med 2003:9(6):477-83.

[57] Grandner MA, Patel NP, Gehrman PR, et al. Who gets the best sleep? ethnic and socioeconomic factors related to sleep complaints. Sleep Med 2010;11(5):470-8

[58] Hawkley LC, Cacioppo JT. Aging and loneliness downhill quickly? Curr Direct Psychol Sci 2007;16(4):187-91.

[59] Patterson AC, Veenstra G. Loneliness and risk of mortality: a longitudinal investigation in alameda county, California. Soc Sci Med 2010;71(1):181-6.

[60] Ailshire JA, Burgard SA. Family relationships and troubled sleep among U.S. adults: examining the influences of contact frequency and relationship quality. J Health Soc Behav 2012;53(2):248-62.

[61] Krishnan P, Hawranik P. Diagnosis and management of geriatric insomnia: a guide for nurse practitioners. J Am Acad Nurse Pract 2008;20(12):590-9.

[62] Morin CM, Espie CA. The oxford handbook of sleep and sleep disorders. Oxford University Press; 2012

[63] Ancoli-Israel S, Vanover KE, Weiner DM, Davis RE, van Kammen DP. Pimavanserin tartrate, a $5-\mathrm{HT}<\mathrm{sub}>2 \mathrm{~A}$ receptor inverse agonist, increases slow wave sleep as measured by polysomnography in healthy adult volunteers. Sleep Med 2011;12(2):134-41.

[64] Viola AU, Chellappa SL, Archer SN, et al. Interindividual differences in circadian rhythmicity and sleep homeostasis in older people: effect of $\mathrm{a}<\mathrm{i}>$ PER3 polymorphism. Neurobiol Aging 2012;33(5):1010. e17-27.

[65] Center for Disease Control and Prevention (CDC). Perceived insufficient rest or sleep among adults - United States, 2008. MMWR Morb Mortal Wkly Rep 2009;58(42):1175-9.

[66] Arber S, Meadows R. Social and health patterning of sleep quality and duration. Understanding Society; 2011. p. 13.

[67] Hurst M. Who gets any sleep these days? Sleep patterns of Canadians. Can Soc Trends 2008;11-008.

[68] Leach LS, Christensen H, Mackinnon AJ, Windsor TD, Butterworth P. Gender differences in depression and anxiety across the adult lifespan: the role of psychosocial mediators. Soc Psychiatry Psychiatr Epidemiol 2008;43(12):98398.

[69] Unruh AM. Gender variations in clinical pain experience. Pain 1996;65(2):12367. 